\title{
The concentration of PM10 in the atmospheric surface layer of Krasnoyarsk in the period of unfavorable meteorological conditions
}

\section{V. Zavoruev, E. N. Zavorueva}

V. V. Zavoruev, E. N. Zavorueva, "The concentration of PM10 in the atmospheric surface layer of Krasnoyarsk in the period of unfavorable meteorological conditions," Proc. SPIE 10466, 23rd International Symposium on Atmospheric and Ocean Optics: Atmospheric Physics, 1046673 (30 November 2017); doi: 10.1117/12.2288754

Event: XXIII International Symposium, Atmospheric and Ocean Optics, Atmospheric Physics, 2017, Irkutsk, Russian Federation 


\title{
The concentration of $\mathrm{PM}_{10}$ in the atmospheric surface layer of Krasnoyarsk in the period of unfavorable meteorological conditions
}

\author{
V.V. Zavoruev ${ }^{1,2}$, E.N. Zavorueva ${ }^{2}$ \\ ${ }^{1}$ Institute of computational modeling SB RAS, Akademgorodok, 660036 Krasnoyarsk, Russia; \\ ${ }^{2}$ Siberian federal university, 79 Svobodny pr., 660041 Krasnoyarsk
}

\begin{abstract}
The periods of unfavorable meteorological conditions (UMC) do not coincide with the periods of contamination of suspended particles $\mathrm{PM}_{10}$. There are cases when during the regime of the UMS is not happening the pollution of the atmosphere by aerosol particles. At UMC the pollution of suspended particles in different parts of the city differs as the concentration of the aerosol and the duration of the negative impact on people's health.
\end{abstract}

Keywords: $\mathrm{PM}_{10}$, unfavorable meteorological conditions (UMC), Krasnoyarsk.

\section{INTRODUCTION}

In Krasnoyarsk climatic conditions are very unfavorable for dispersion of pollutants. The city is located in the area of high air pollution potential. During the last seven years in Krasnoyarsk there is a tendency of increasing the number of days with unfavorable meteorological conditions (UMC): 2010 - 16,5; 2011 - 34,5; 2012 - 44; 2013 - 27; 2014 - 40; 2015 - 67; 2016 - 58 days. Frequent air stagnation leads to the accumulation of pollutants in the atmosphere. For many years the priority air pollutants are benzo(a)pyrene, formaldehyde, nitrogen dioxide, suspended substances.

In 2015 year the total emissions into the atmosphere of Krasnoyarsk amounted to 195 thousand tons, including 128,7 thousand tons from stationary sources.

During periods of UMC the inhabitants of the city called "black sky" the visually visible aerosol pollution of the atmosphere. The scientific name for this phenomenon was smog. Unfortunately comprehensive scientific investigations of the mechanisms and nature of aerosol pollution of the atmosphere of the city, which is home to more than a million people, still have not carried out.

Ecological monitoring of concentrations of aerosol (suspended particles $\mathrm{PM}_{10}$ ) in the atmosphere of Krasnoyarsk has been carried out since the end of 2011 year. These observations are carried out by the Center of implementation of measures for nature and environmental protection of Krasnoyarsk region (CIMNandEP). The large amount of data on the concentration of aerosol in the atmospheric surface layer has been obtained.

The aim of the paper is to analyze this information from the position of influence of meteorological conditions, as well as to consider the annual dynamics of the average monthly concentrations of $\mathrm{PM}_{10}$ in different parts of the city.

\section{THE DATA USED}

The scheme of location of automated monitoring stations (AMS) for air pollution and the measurement results are presented on the site http://krasecology.ru.

Data on the periods of UMC are published on the website of the Federal State Budget Office "Sredneosibirskoye Department for Hydrometeorology and Environmental Monitoring" - http://meteo.krasnoyarsk.ru/.

\section{APPARATUS FOR MEASURING CONCENTRATION OF AEROSOL PARTICLES}

The combo semi-automatic dust OMPN-10,0 used to measure the mass concentration of aerosol particles of different origin and chemical composition in the atmospheric air. 
The principle of the dust is based on the complex use of optical and gravimetric methods and consists of detecting scattered radiation by an optical sensor and parallel forced pumping of the analyzed air sample through an AFA-VP-10 analytical aerosol filter (AFA-VP-20).

The optical unit provides a measurement of the concentration of suspended particles in continuous conditions in the standard RM-10 (when using the appropriate impactor).

The beam of the He-Ne laser illuminates the measuring chamber through which the analyzed air sample is pumped. Aerosol particles in the beam trajectory scatter light. Direct radiation gets into light trap, which is an absolutely black body, in which it is completely absorbed. The photodetector registers the radiation at an angle of $90^{\circ}$, whose integral values of intensity are proportional to the concentration of aerosol particles.

When exceeding the values of the mass concentration of aerosol particles of the alarm threshold set on the optical unit, electroactivator automatically turns and sampled air analyzed on an analytical filter. After that in the laboratory determination of the mass concentration of aerosol particles by gravimetric method for correct the calibration characteristics of the optical Assembly is conducted.

\section{RESULTS AND DISCUSSION}

One of the main polluters of the atmosphere of the city is the plant of RUSAL, which produces over a million tons of aluminum per year. At a distance of 5-10 km from the aluminum plant there are five monitoring stations of the regional (CIMNandEP) monitoring system. Three posts are within the city limits and two in the suburbs. Because the periods UMC are declared only for Krasnoyarsk, it will be correct to consider the results of observation posts on the city: "Krasnoyarsk - North", "Krasnoyarsk - Solar", " Krasnoyarsk - Cheremushki".

It should be said that for technical reasons a series of observations of the concentrations of suspended particles have time gaps. Moreover, since the beginning of 2015 year, the measurement in positions "Krasnoyarsk - North" and "Krasnoyarsk - Solar" stopped, and the end of 2016 year - at the post " Krasnoyarsk - Cheremushki".

The average annual concentrations of $\mathrm{PM}_{10}$ in the area of AMS are shown in table 1. The level of air pollution is calculated in relation to the average annual maximum permissible concentration (MPC) for $\mathrm{PM}_{10}$, which is equal to 0,04 $\mathrm{mg} / \mathrm{m}^{3}$.

Table 1. Average annual concentrations of $\mathrm{PM}_{10}\left(\mathrm{C}, \mathrm{mg} / \mathrm{m}^{3}\right)$ and pollution level (C/MPC) in the area of AMS CIMNandEP

\begin{tabular}{|c|c|c|c|c|c|c|c|c|c|c|}
\hline \multirow{2}{*}{ AПН } & \multicolumn{2}{|c|}{2012} & \multicolumn{2}{|c|}{2013} & \multicolumn{2}{|c|}{2014} & \multicolumn{2}{|c|}{2015} & \multicolumn{2}{|c|}{2016} \\
\cline { 2 - 10 } & $\mathrm{C}$ & $\mathrm{C} / \mathrm{MPC}$ & $\mathrm{C}$ & $\mathrm{C} / \mathrm{MPC}$ & $\mathrm{C}$ & $\mathrm{C} / \mathrm{MPC}$ & $\mathrm{C}$ & $\mathrm{C} / \mathrm{MPC}$ & $\mathrm{C}$ & $\mathrm{C} / \mathrm{MPC}$ \\
\hline $\begin{array}{c}\text { «Rrasnoyarsk - } \\
\text { North» }\end{array}$ & 0,114 & $\mathbf{2 , 8 5}$ & 0,0514 & $\mathbf{1 , 2 8}$ & 0,029 & 0,73 & & & & \\
\hline $\begin{array}{c}\text { «Rasnoyarsk - } \\
\text { Solar» }\end{array}$ & 0,056 & $\mathbf{1 , 3 9}$ & 0,0479 & $\mathbf{1 , 2 0}$ & 0,051 & $\mathbf{1 , 2 8}$ & & & & \\
\hline $\begin{array}{c}\text { «Krasnoyarsk } \\
\text { Cheremushki» }\end{array}$ & & 0,0516 & $\mathbf{1 , 2 9}$ & 0,031 & 0,78 & 0,053 & $\mathbf{1 , 3 3}$ & 0,054 & $\mathbf{1 , 3 5}$ \\
\hline
\end{tabular}

From the data presented in table 1 it follows that an aerosol pollution of the atmosphere, which is fixed in the area of at least one post takes place annually.

In the State report "On condition and protection of the environment in the Krasnoyarsk region" for 2012-2015 years information is presented about pollution with suspended solids, for which MPC daily average (MPCda) is $0.15 \mathrm{mg} / \mathrm{m}^{3}$. The level of air pollution by suspended solids was in 2012-1,52; $2013-1,04 ; 2014-0,65 ; 2015-0,93$. The tendency of suspended solids and suspended particles is similar to the AMS "Krasnoyarsk - North" and " Krasnoyarsk Cheryomushki" and is not the same as AMS "Krasnoyarsk - Solar".

Dynamics of monthly average concentrations of $\mathrm{PM}_{10}$ at three urban AMS in 2013-2014 years are presented in figures 1 and 2. 


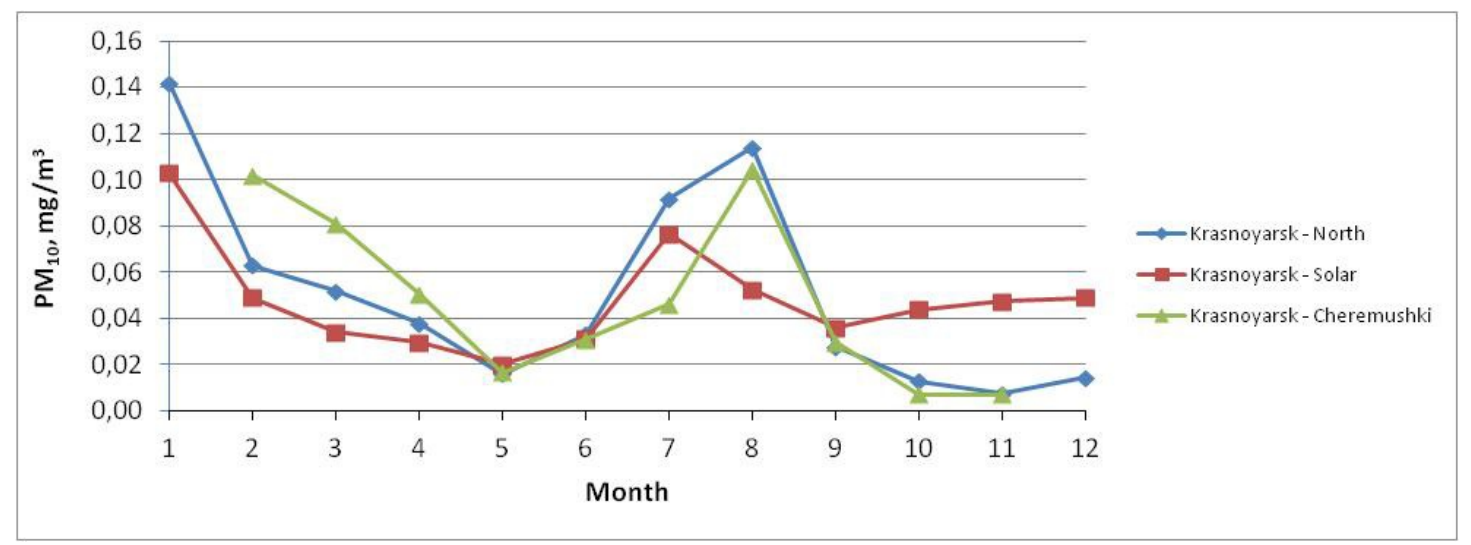

Figure 1. Change of monthly average concentration of $\mathrm{PM}_{10}$ at the AMS "Krasnoyarsk - North", "Krasnoyarsk - Solar" and " Krasnoyarsk - Cheryomushki" in 2013 year

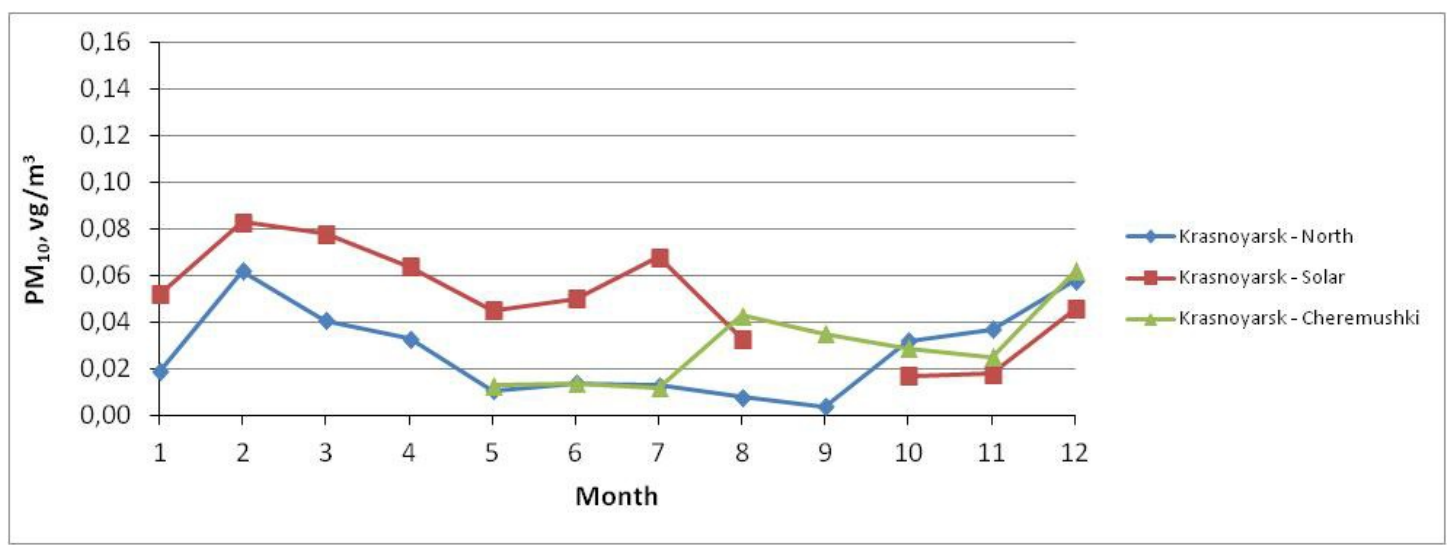

Figure 2. Change of monthly average concentration of $\mathrm{PM}_{10}$ at the AMS "Krasnoyarsk - North", "Krasnoyarsk - Solar" and " Krasnoyarsk - Cheryomushki" in 2014 year

From the analysis of the data presented in Fig. 1 and 2 it follows that for each observation station, the annual average dynamics in 2013 year was significantly different from the dynamics in 2014 year. In addition, during one year the annual average dynamics at the AMS "Krasnoyarsk - North", "Krasnoyarsk - Solar" and " Krasnoyarsk - Cheryomushki" differed from each other. The reasons for these differences can be due to many factors, among which we should point out the difficult terrain, the unfrozen waters of the Yenisei river and mixed wind flows in the surface layer of the urban area [1].

Thus, it is not revealed inter-annual change pattern of change in the monthly average concentration of $\mathrm{PM}_{10}$ in the surface layer of the atmosphere of the city of Krasnoyarsk.

Now let's analyze the influence of UMC on the concentration of aerosol particles. Thus it is necessary to make the following important remark - on the website http://meteo.krasnoyarsk.ru declared periods of the forecast of UMC first and second degree of danger. UMC second degree of danger are declared once in several years. In this work such situations will not be considered.

The aerosol pollution of the atmosphere which was observed in the post "Krasnoyarsk - North" from 15 July-15August 2012 year is considered (Fig. 3). It is seen that almost over the whole observation period the concentration of $\mathrm{PM}_{10}$ exceeded the daily average MPC (MPCda $\left.=0,06 \mathrm{mg} / \mathrm{m}^{3}\right)$. For a long time the exceeding of one time concentration MPC (MPCot $=0.3 \mathrm{mg} / \mathrm{m}^{3}$ ) were recorded: from 03-00 on 31 July to 14: 00 hours on 2 August and from 23: 00 hours on August 3 to 08: 00 on 6 August. During the same periods the maximum concentrations of $\mathrm{PM}_{10}$ were recorded. The 
decrease of $\mathrm{PM}_{10}$ concentrations. in the period from 14.00 on 2 August to 23-00 on 3 August, probably due to short-term exposure of the wind of the western direction. The purification of the atmosphere from aerosol particles began on August 6 with the emergence of dominant south-west winds.

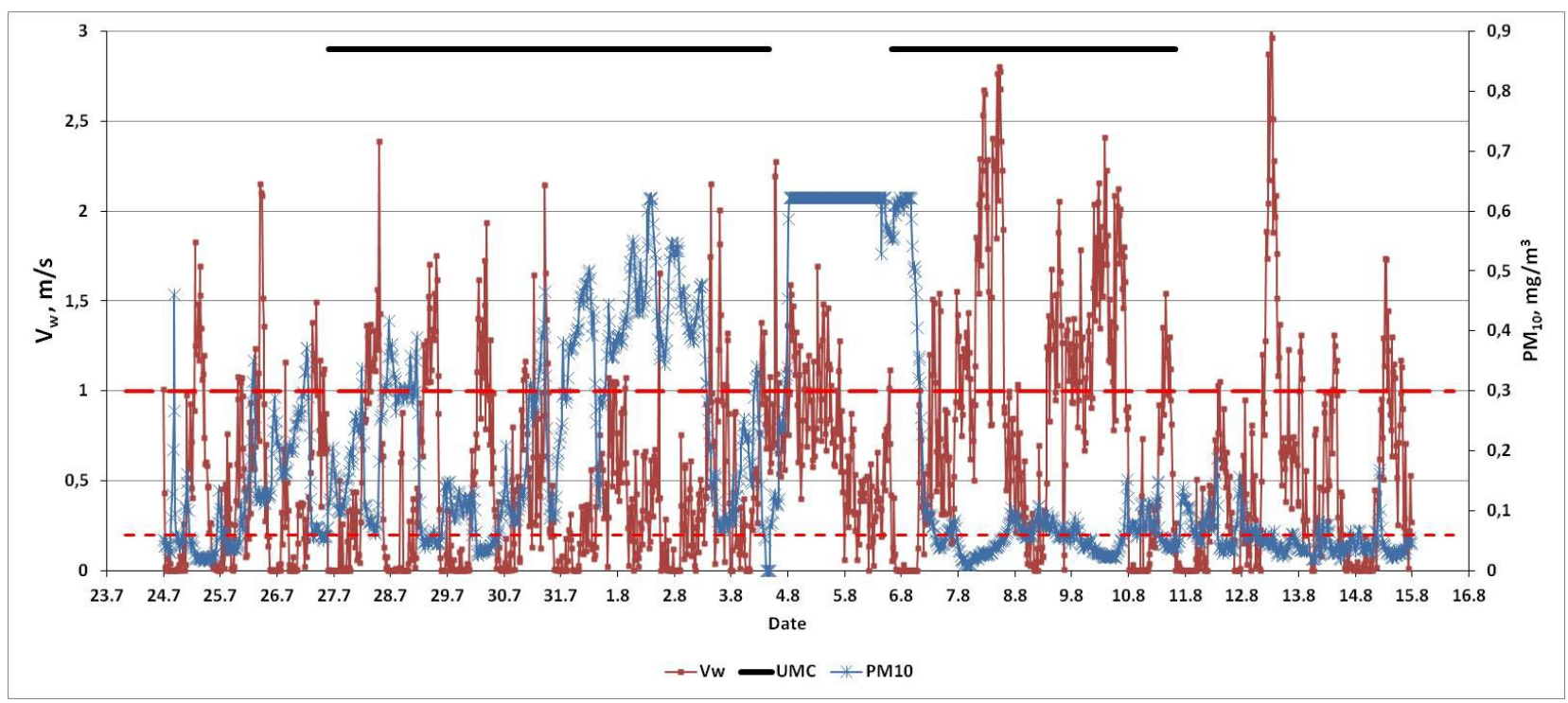

Figure 3. The wind speed $\left(\mathrm{V}_{\mathrm{w}}\right)$ and the concentration of $\mathrm{PM}_{10}$ at the post "Krasnoyarsk - North", 15 July-15August 2012 year. The line with short dashes corresponds to MPCda, the thick black line in the top graph shows values MPCot, the thick black line at the top of the chart shows the period of the forecast of UMC

In the period of the forecast of UMC concentration of suspended particles was differently changed (Fig. 3). If the period of the first UMC (from 22: 00 hours on 26 July to 16: 00 hours on August 3) during one hundred hours the exceeding the MPSot was observed, in the second period UMC (from 20: 00 hours on 5 August to 20: 00 on August 10) that the excess was about ten o'clock.

The period forecast UMC was more than the period of the observed real air pollution by suspended particles (Fig. 4).

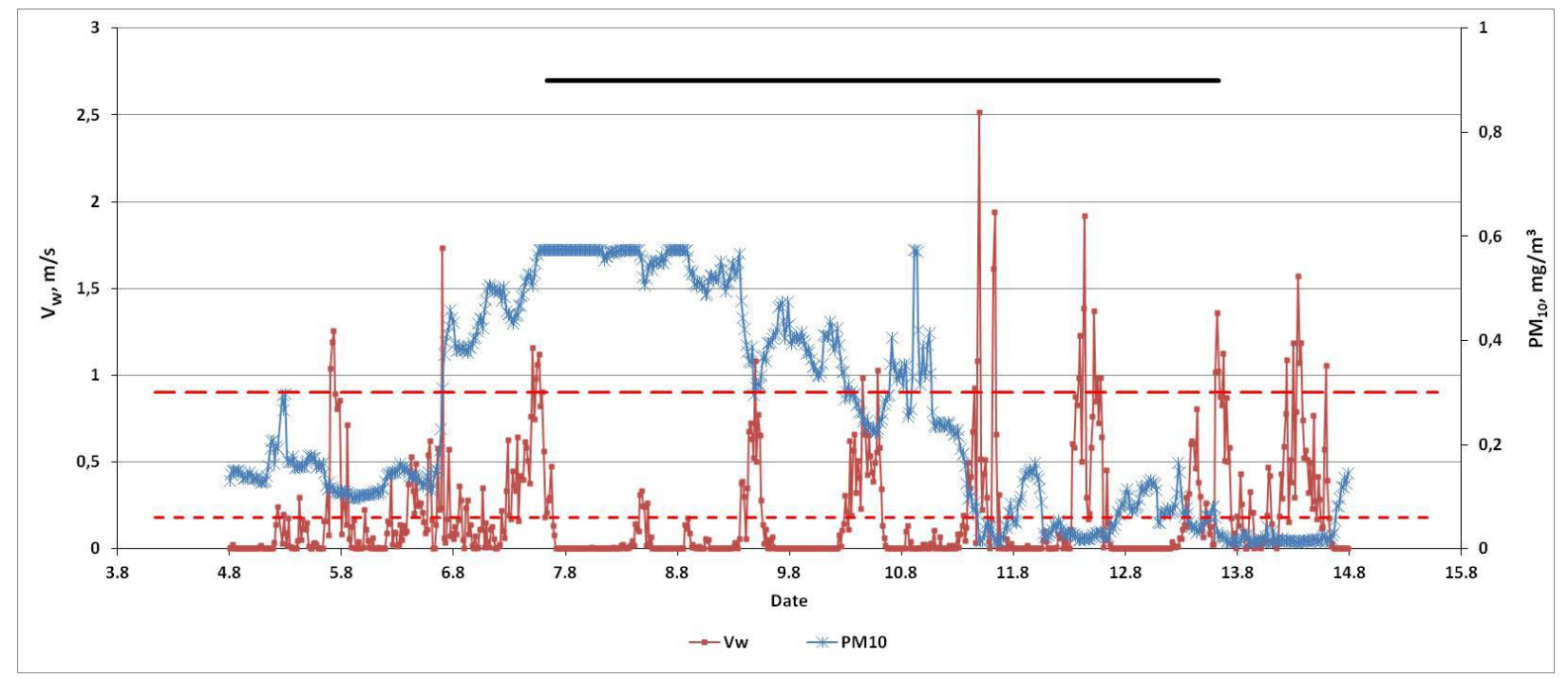

Figure 4. The wind speed and the concentration of $\mathrm{PM}_{10}$ at the post "Krasnoyarsk - North", August 2013year. The legend as in Fig. 3 
Prior to the forecasted UMC (beginning at 20:00 on August 6, ending at 20:00 on August 12, 2013 year) on August 5 from 20-40 hours to 23-40 hours there was a sharp increase of the $\mathrm{PM}_{10}$ concentration from $0,15 \mathrm{mg} / \mathrm{m}^{3}$ to $0,44 \mathrm{mg} / \mathrm{m}^{3}$ (Fig. 4). At this moment the east wind blew, $\mathrm{V}_{\mathrm{w}}$ was equal to $1,7 \mathrm{~m} / \mathrm{s}$. Until the middle of the UMC period the $\mathrm{PM}_{10}$ concentration exceeded the MPCot and the concentration of suspended solids sharply decreased with the occurrence of the south-west wind gusts to 2,5 m/s 11 August from 14-20 hours to 15-20 hours.

Thus, the beginning of atmospheric pollution (exceeding MPCot) and the beginning of the forecasted UMC period often do not coincide in time. In addition, the duration of the forecast UMC does not correspond to the duration of air pollution by suspended particles

Recall that the influence of UMC is projected on the entire territory of Krasnoyarsk. In this regard the air pollution by aerosol particles in the period UMC on all three APS is compared. The analysis is performed for the last decade of June 2014 year. The forecast of UMC was announced from 20: 00 hours on 25 June, the end 20-00 hours on June 27. Wind speed and $\mathrm{PM}_{10}$ concentration at the three posts of AMS are shown in figures 5-7.

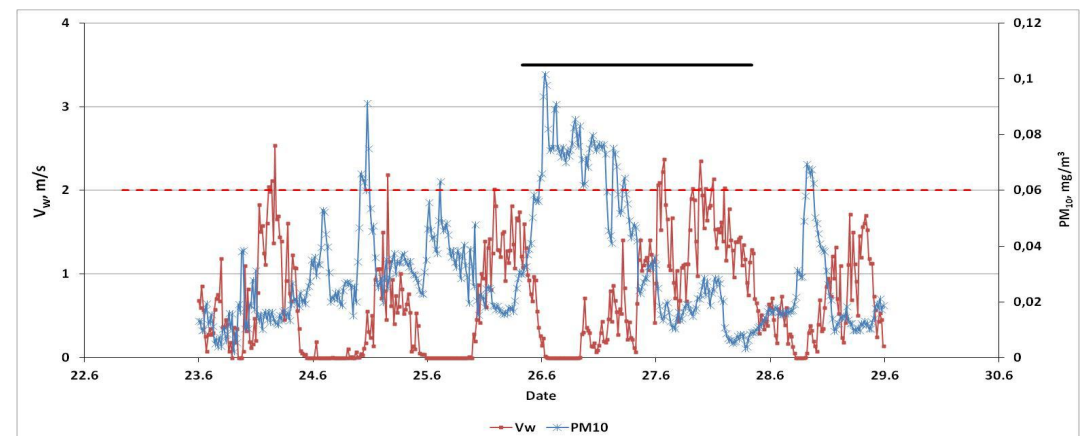

Figure 5. The wind speed and the concentration of $\mathrm{PM}_{10}$ at the post "Krasnoyarsk - North", June 2014 year. The legend as in Fig. 3

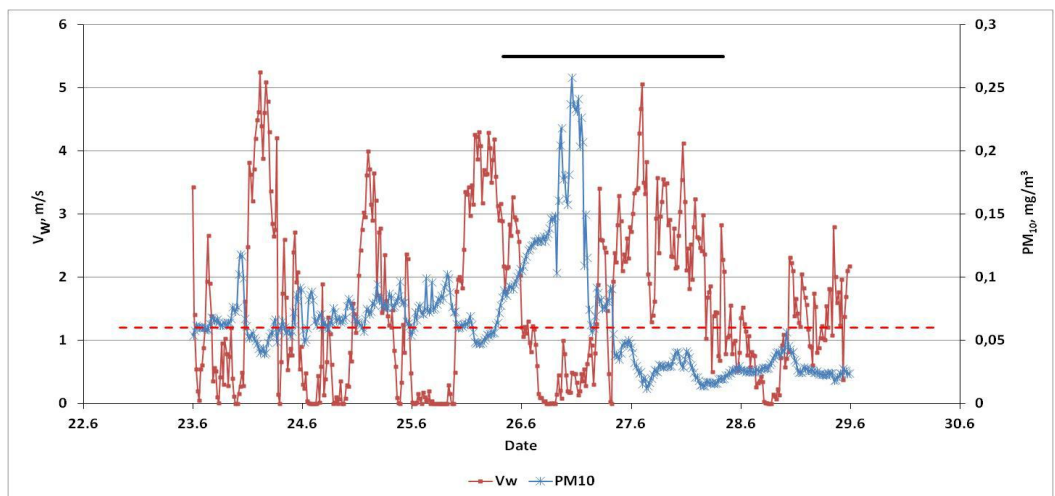

Figure 6. The wind speed and the concentration of $\mathrm{PM}_{10}$ at the post "Krasnoyarsk - Solar", June 2014 year. The legend as in Fig. 3

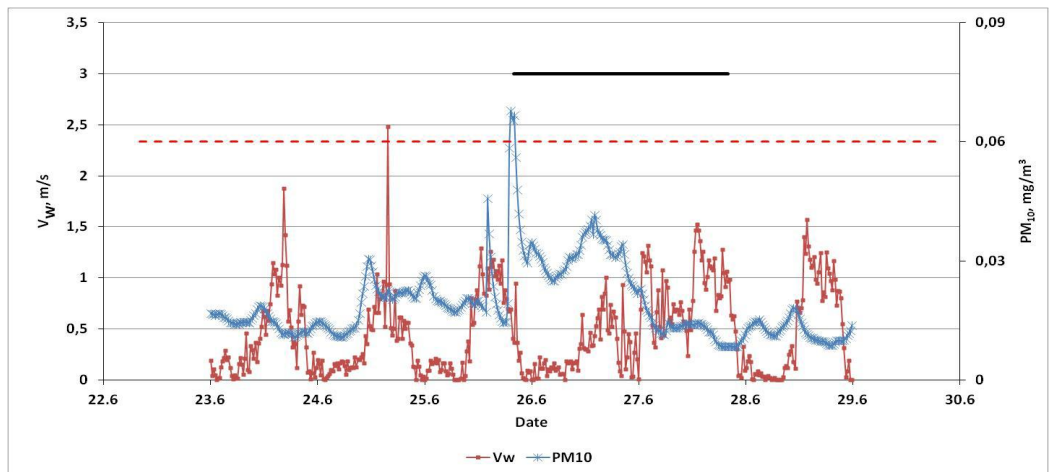

Figure 7. The wind speed and the concentration of $\mathrm{PM}_{10}$ at the post "Krasnoyarsk - Cheryomushki", June 2014 year. The legend as in

Fig. 3 
At the post "Krasnoyarsk - Solar" (Fig. 5) the opposite of the curve of $\mathrm{PM}_{10}$ concentrations and wind speed clearly traced. Moreover, in the forecast period of UMC this course changes slightly. At two other city positions such pattern was not (Fig. 6 and 7).

In the period of UMC the concentration of suspended particles at all three posts did not exceed MPCot. At the post "Krasnoyarsk - Solar" the concentration of $\mathrm{PM}_{10}$ was higher than the MPCda before the beginning of the UMC, in the initial period of the UMC it increased by 4 times and in the second half of UMC fell below MPCda (Fig. 6). The maximum concentration of $\mathrm{PM}_{10}$ was registered at the post "Krasnoyarsk - Solar" - 0,26 $\mathrm{mg} / \mathrm{m}^{3}$ and the minimum concentration at the post " Krasnoyarsk - Cheryomushki" - 0,07 mg/m $\mathrm{m}^{3}$. The duration of exceeding of the MPCot in the forecast UMC period was: in the Solar area 24 hours, in the North area 18 hours; in Cheryomushki - 0,17 hours.

Thus, the influence of forecast UMC on aerosol pollution is not equally manifested in various parts of the city.

Air quality index (AQI) characterizes the pollution of the atmosphere from the position of influence on human health. The threshold value of the negative influence begins with a value of 100. Dynamics of AQI at the post "Krasnoyarsk Cheryomushki" in 2016 year is shown in Figure 8.

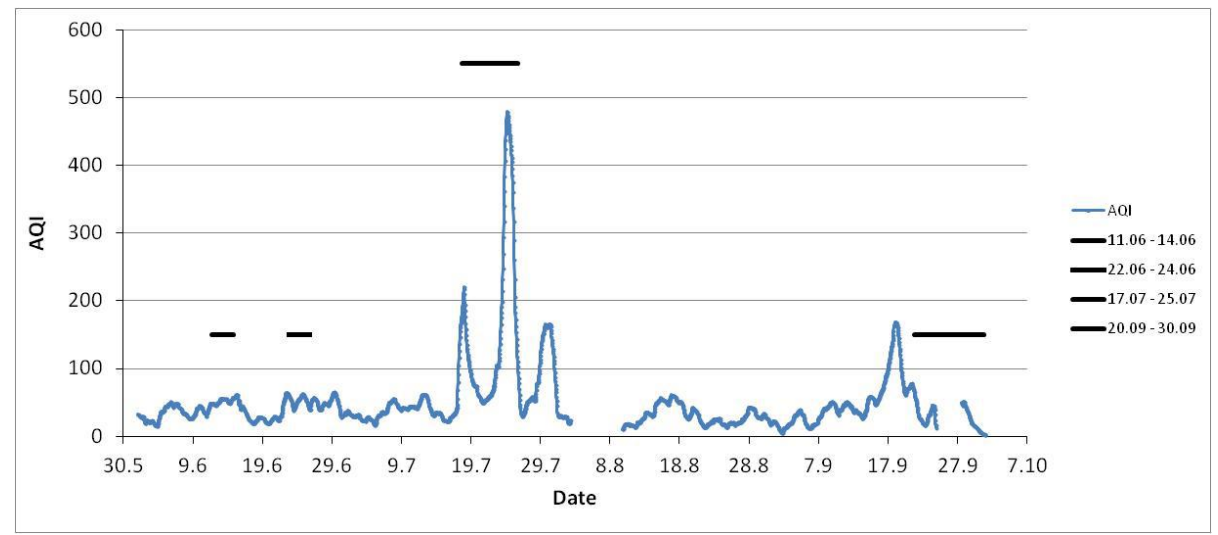

Figure 8. Change of the AQI value (for suspended particles of $\mathrm{PM}_{10}$ ) at the post "Krasnoyarsk - Cheryomushki" in 2016 year. Thick black horizontal lines indicate periods of forecast UMC

The data presented clearly demonstrate that the forecast UMC rarely affect aerosol pollution of the ground atmospheric layer in Krasnoyarsk. In most cases during periods of UMC the concentration of suspended particles does not increase to levels dangerous for both human health and photosynthesis of plants [2].

\section{CONCLUSIONS}

1. In 2012-2016 years the surface layer of the atmosphere of Krasnoyarsk was contaminated with suspended particles of $\mathrm{PM}_{10}$.

2. The interannual pattern of changes of monthly average concentrations of $\mathrm{PM}_{10}$ has not been identified.

3. The UMC forecast periods do not coincide with the periods of contamination of suspended $\mathrm{PM}_{10}$ particles. There are cases when, during the regime of the UMC is not happening the pollution of the atmosphere by aerosol particles.

4. At UMC the pollution of suspended particles in different parts of the city distinguished as the concentration of the aerosol and the duration of the negative influence on people's health.

\section{REFERENCES}

[1] Hrebtov, M. and Hanjalić, K. Numerical study of winter diurnal convection over the city of Krasnoyarsk: Effects of non-freezing river, undulating fog and steam devils, Boundary-Layer Meteorology 163, Issue 3, 469-495 (2017).

[2] Zavorueva, E.N. and Zavoruev, V.V. Fluorescence parameters of leaves of trees and shrubs during period of adverse weather conditions in Krasnoyarsk, Proc. of SPIEV 9680, 968067 (2015). 